\title{
Remediation of Oiled Land
}

\author{
Bekuzarova S.A. \\ Department of agriculture, plant cultivation, \\ selection and seed production \\ Gorsk State Agrarian University \\ Vladikavkaz, Russia \\ Kh. Ibragimov Complex Institute \\ of the Russian Academy of Sciences \\ Grozny, Russia \\ e-mail: bekos37@mail.ru \\ Gaplayev M.Sh. \\ Chechen Agricultural Research Institute
Grozny, Russia
chechniish@mail.ru
}

Bekmurzov A.D.

North-Ossetian State University,

Vladikavkaz, Russia

e-mail: bekos37@mail.ru

Dulayev T.A.

Gorsk State Agrarian University

Vladikavkaz, Russia

\author{
Zaalishvili V.B. \\ Biological research department \\ Kh. Ibragimov Complex Institute \\ of the Russian Academy of Sciences \\ Grozny, Russia \\ e-mail: vzaal@mail.ru
}

\author{
Lazarov T.K. \\ Faculty of Agronomy \\ Gorsk State Agrarian University \\ Vladikavkaz, Russia \\ Vladikavkaz, Russia \\ t-101271@yandex.ru
}

Lushchenko G.V.

North Caucasian Research Institute of Mountain and Piedmond agriculture, Vladikavkaz Scientific Centre, RAS Vladikavkaz, Russia

\author{
Dzampayeva M.V. \\ Gorsk State Agrarian University \\ Vladikavkaz, Russia
}

\begin{abstract}
To reduce the toxicity of oiled land plantsaccumulators were used. Para-aminobenzoic acid and the biological preparation Baikal EM-1 were used with biologics and zeolite-containing clays. It was found that seeding accumulating plants treated with the Baikal EM-1 biological product, repeated watering and sweetening with an aqueous solution of a Stevia plant the concentration of oil in the soil and the number of hydrocarbons significantly reduces (from 3.2 to $0.8 \%$ ). At the same time lead and cadmium decrease to maximum permissible concentrations.
\end{abstract}

Keywords- environment, plants-accumulators, oil products, soil toxicity.

\section{INTRODUCTION}

Oil is the most dangerous of environmental pollutants. Large volumes of oil get in the ecosystem as a result of accidents during transportation, illegal tie-ins to oil pipelines, disturbances in production, etc. Not being a xenobiotic, oil can nevertheless exhibit strong contaminating properties, when it is extracted from the subsoil to the surface of the earth. Getting into the soil, oil has a toxic effect on plants and animals, inhibits the activity of the soil microbiota and disrupts the balance of soil enzymes. In this regard, the problem of diagnosing the toxic effect of petroleum hydrocarbons on a multi-level soil ecosystem is acute $[1,2]$.

Environment conservation in the country and in the world should be aimed at reducing the impact on the nature of hazardous industries. For this purpose, it is necessary to create new technologies that can capture, recycle, dispose of pollutants or toxins, mitigating or preventing their impact on the environment. The problem of developing new and improving existing technologies, eliminating the effects of man-made contamination with oil and oil products, and restoring the biological potential of disturbed ecosystems remains a pressive problem, since the area of land and water polluted with oil increases every year. [3,4].

Environmental pollution by oil and oil products (OP) is one of the main and most common. Their sources can be fuel spills during transportation or storage, residual unburned fuel in the exhaust gases of internal combustion engines. Natural sources of oil pollution play a minimal role in the overall 
environmental pollution by oil hydrocarbons when leaving the surface of oil-bearing rocks $[4,5]$.

Petroleum products are a standardized type of pollution. In the Russian Federation, the maximum permissible concentration (MPC) of petroleum products in water $(0.1 \mathrm{mg} /$ 1 for kerosene, $0.1-0.3 \mathrm{mg} / 1$ for oil), and water bodies for fisheries, $0.05 \mathrm{mg} / 1$ are established [6].

Existing mechanical, thermal and physico-chemical methods for cleaning soils from oil pollution are expensive and effective only at a certain level of pollution (usually not less than $1 \%$ of oil in the soil). They are often associated with the additional introduction of pollution and they do not provide complete cleaning. Currently, the most promising method for the purification of oil-polluted soils is the biotechnological approach based on the use of various groups of microorganisms characterized by an increased ability to biodegrade components of oil and oil products.

Keeping the soil moist is one of the agrotechnical methods of controlling biological activity, and it has an effective impact on the rate of decomposition of petroleum and petroleum products. Favorable water regime of the soil reaches by irrigation. Improving the water regime by irrigation causes the improvement of the agrochemical properties of the soil. It affects the mobility of nutrients, microbiological activity and activity of biological processes. At the same time, the effect on the microbiological and enzymatic activity of agrochemical methods, for example, fertilization, loosening, is enhanced.

Soil acidity plays an important role in the decomposition of petroleum and petroleum products. $\mathrm{A} \mathrm{pH}$ value close to neutral is optimal for the growth of most bacterial microorganisms on hydrocarbons. In acidic podzolic soils, this factor is crucial in the decomposition of petroleum and petroleum products. Therefore, to create a $\mathrm{pH}$ that is optimal for their biodegradation, acidic soils are affected by liming.

Sowing alfalfa and other grasses on the oil-contaminated soil, herbs with an extensive root system helps to accelerate the decomposition of hydrocarbons. The positive impact of crops of agricultural plants, and in particular perennial grasses, is explained by the fact that with their developed root system they contribute to the improvement of the gas-air regime of polluted soil, enrich the soil with nitrogen and biologically active compounds released by the root system into the soil during plant life. All this stimulates the growth of microorganisms and, accordingly, intensifies the decomposition of petroleum and petroleum products.

However, not every bio-facility can be used as an indicator of external influence. For this, a bio-facility should have a high sensitivity with low individual variability, genetic homogeneity, facilities used for bioindication, if possible in large quantities and with homogeneous properties, the possibility of existence in a wide range of environmental conditions, ease of indication in nature, high life expectancy, reproducibility of results obtained using a specific test system, complexity in terms of the possibility of registering different biological effects (mutagenic, toxic, teratogenic) on the same test object, the speed of obtaining information [3].
Using these capabilities of bio-facilities, plants, we have identified some phytoindicators that allow to determine the state of the environment of a certain territory.

The ability of plants to absorb metal from polluted soils is different, since the root systems of different plant species can, to varying degrees, limit the intake of metal into aboveground organs.

Lead, chromium, and mercury absorbed by the roots are subjected to strong binding: only a small part of them are transferred to aboveground plants.

The distribution of metals in plant organs is clearly pronounced acropetal in nature: roots $>$ stalks $>$ leaves $>$ fruits, indicating the plants have a protective mechanism. It prevents the entry of toxicants from the roots into the elevated organs. The tendency is less obvious on soils with a normal metal content and stronger with an excess.

Studying perennial grasses as green manure crops (motley knotted, alfalfa, espartret, clover), it was determined that the content of mobile forms of zinc, copper, nickel, cobalt, manganese, soil iron increases from the stalking phase to the flowering phase of the studied plants.

Thus, in alfalfa seed (Medicago Sativa L.) in the flowering phase, the content of mobile forms of heavy metals in the soil increases: zinc - from 40.1 to $43.2 \mathrm{mg} / \mathrm{kg}$, copper -12.8 to $15.9 \mathrm{mg} / \mathrm{kg}$; Nickel - from 13.5 to $16.2 \mathrm{mg} / \mathrm{kg}$; cobalt - 10 to $11.7 \mathrm{mg} / \mathrm{kg}$; manganese -580 to $710 \mathrm{mg} / \mathrm{kg}$, and finally, iron - from 360 to $440 \mathrm{mg} / \mathrm{kg}$.

It should be noted that the maximum concentration of mobile zinc and copper in the soil accumulated during the budding phase of the studied legumes. Thus, the variegate lath removes up to $44.7 \mathrm{mg} / \mathrm{kg}$ of zinc and $20.43 \mathrm{mg} / \mathrm{kg}$ of copper from the soil; sainfoins up to $54.0 \mathrm{mg} / \mathrm{kg}$ zinc and up to 31.5 $\mathrm{mg} / \mathrm{kg}$ copper; alfalfa - up to $99.2 \mathrm{mg} / \mathrm{kg}$ zinc and $32.4 \mathrm{mg} / \mathrm{kg}$ copper.

In recent years, high sorption abilities have been revealed in various amaranth cultures. This ability amaranth acquired due to the accumulation of leaves of high calcium content, which varies from 8 to $26 \%$ depending on soil and climatic conditions. The important feature of amaranth is the accumulation of silicon compounds (organogenic, soluble polymeric, total). It absorbs toxic elements (including hydrocarbons from oil-contaminated lands) and accelerates the processes of soil fertility recovery $[7,8,9,10,11,12]$.

\section{Methods AND MATERIALS}

In order to speed up the cleaning and recultivation of lands contaminated with oil and oil products, amaranth was sown in a mixture with alanite-zeolite-containing clay in the amount of 0.8-1 tons per hectare; and in the beginning of ripening phase the plants were mown and plowed into the soil. The following year, sowing of leguminous grass mixtures of perennial grasses containing $50-60 \%$ of leguminous plants with their subsequent tilling in the flowering phase was carried out

The following year, sowing of leguminous grass mixtures of perennial grasses containing $50-60 \%$ of leguminous plants 
with their subsequent tilling in the flowering phase was carried out.

The studies were carried out in conjunction with the Center for Geophysical Research of the Vladikavkaz Scientific Center of the Russian Academy of Sciences, as well as the Complex Research Institute of the Russian Academy of Sciences (Grozny) in areas polluted with oil and oil products. The chemical analyzes on the content of toxic substances were determined in Gorsky State Agrarian University (Vladikavkaz).

A PABA working fluid was prepared at the rate of $100 \mathrm{~g}$ of powder per 10 liters of water with a temperature of $800 \mathrm{C}$. Stevia leaves were put in hot water in an amount of $200 \mathrm{~g}$. In the absence of fresh leaves, stevia preparations were used. In this case, $20 \mathrm{ml}$ of stevia solution per 10 liters of liquid was used. A solution of the biological preparation Baikal EM-1 was prepared at the same time at the rate of 1 part per 100 parts of water, that is, $100 \mathrm{~g}$ of the biological preparation per 10 liters of water. After cooling the solution PABA to 10-250 $\mathrm{C}$ mixed two solutions, the sum of which amounted to 20 liters. This amount of solution irrigated the area polluted with oil of $10 \mathrm{~m} 2$ of vegetation organisms.

The principal difference of the drug Baikal-EM-1 from other microbiological preparations is its multicomponent nature, without harm to humans, animals, and the entire microflora of the soil.

The use of this biological product allows to solve problems associated with the natural fertility of the soil, preventing pollution of the environment Baikal-EM-1 provides water and air permeability of the soil to a depth of $60-80 \mathrm{~cm}$.

The processes of humus formation are several times accelerated within 2-3 weeks due to the introduction of this biological product into the toxic soil.

Usually, to stimulate microorganisms, sweets are added to the solution: jam, honey, sugar.

In contrast to the known methods, in the proposed method, Stevia plants (Stevia rebaudiana) are used as sugar substitutes of plant origin. Stevia leaves are 10 to 15 times sweeter than sugar. Stevia has many antioxidants (quacetin, rutin), mineral substances (calcium, phosphorus, potassium, zinc, chromium, magnesium, selenium, copper), as well as vitamins of groups A, B, C, E. In addition, 53 active substances (including stevioside) contribute to the revival and activity of microorganisms.

Such a mixture with the help of PABA sweetened with stevia enhances the activation of Baikal-EM-1 microorganisms; and within 2-3 weeks the amount of oil hydrocarbons in the soil is significantly reduced. The parameters of the method (2-3 weeks) is explained by the activation of microorganisms in the soil using the introduced biological products dissolved in PABA mixed with sweetening of stevia plants. It speeds up the process of humus formation.

After improving fertility, amaranth culture was sown. It is resistant to soil toxicity and possessing high sorption properties to absorb heavy metals.

In the branching phase, in order to stimulate the growth of amaranth, it was re-watered in the same concentration, which simultaneously provides cleaning from oil products.

As a result of the research, it was found that the use of amaranth on polluted soil and plowing up green mass at the beginning of seed ripening cleans the soil from toxic substances. By the time of this phase of development, a good above-ground mass is accumulated, and its incorporation into the soil together with partially ripened seeds (which will come up next year) ensures the supply of an enough organic substances, processes contributing to accelerated decomposition and reduction of toxicity.

\section{RESUlts}

The results of the study showed that when using this method of reducing the amount of petroleum products from 3.2 to $0.2 \mathrm{mg} / \mathrm{kg}$, lead from 12.08 to $0.92 \mathrm{mg} / \mathrm{kg}$, and cobalt from 5.86 to $1.26 \mathrm{mg} / \mathrm{kg}$ dry soil (Table 1 ).

TABLE I.

EFfect Of Amaranth Accumulating Culture On The Reduction Of Heavy Metals In The Soll

\begin{tabular}{|c|c|c|l|l|}
\hline $\begin{array}{c}\text { Oil product (thousand } \\
\mathbf{m g} / \mathbf{k g})\end{array}$ & $\begin{array}{c}\text { Oil concentration, } \\
\mathbf{\%}\end{array}$ & $\begin{array}{c}\text { Lead, } \\
\mathbf{m g} / \mathbf{k g}\end{array}$ & $\begin{array}{c}\text { Cobalt, } \\
\mathbf{m g} / \mathbf{k g}\end{array}$ & \multicolumn{1}{|c|}{ Treatment } \\
\hline 8.6 & 3.2 & 12.08 & 5.86 & Oiled area \\
\hline 3.2 & 1.4 & 5.24 & 2.82 & Sowing of Amaranth \\
\hline 2.6 & 0.6 & 2.62 & 1.92 & Sowing of Amaranth with alanite $0.3-0.5$ tons per hectare \\
\hline 1.5 & 0.3 & 1.82 & 1.64 & Sowing of Amaranth with alanite $0.8-1.0$ tons per hectare \\
\hline 0.6 & 0.2 & 0.92 & 1.26 & $\begin{array}{l}\text { Sowing of Amaranth with alanite }+ \text { sowing perennial grasses for next } \\
\text { year }\end{array}$ \\
\hline
\end{tabular}

TABLE II. DESCRIPTION OF THE EXPERIMENTS FOR REDUCING THE TOXICITY OF THE SOIL

\begin{tabular}{|c|c|c|c|}
\hline Treatment & $\begin{array}{c}\text { Oil concertation, } \\
\text { hectare per kilograms }\end{array}$ & Oil reduction, $\%$ & Hydrocarbon, mg/kg \\
\hline Control (without irrigation) & 66.4 & - & 2680 \\
\hline Watering by the aqueous solution PABA $0.1-0.2 \%$ & 57.0 & 14.2 & 1812 \\
\hline Watering by PABA + stevia + Baikal-EM-1 & 36.8 & 44.1 & 860 \\
\hline Sowing of Amaranth and watering in the phase of branching & 42.5 & 36.0 & 1180 \\
\hline Sowing of Amaranth and watering + Baikal-EM-1 + stevia + second watering & 24.8 & 62.7 & 362 \\
\hline
\end{tabular}


Based on the experiments, we can conclude that sowing herbs with a high sorption capacity: one-year amaranth, perennial grasses (clover, alfalfa, espartset, lash, etc.) provide a hollow rehabilitation of oil-contaminated land for 2 years, which is 2 times faster than in known technologies.

To reduce the toxicity of oiled lands, Russian Academy of Sciences named after N.M. Emmanuel with the Moscow Institute of Biochemical Physics conducted a series of experiments to reduce the toxicity of the soil, where several biological preparations and amaranth sowing as a sorbent of chemical substances were used as ameliorants (Table 2).

This mixture for 2-3 weeks significantly reduces the amount of petroleum hydrocarbons in the soil.

After improving soil fertility, biopreparations were sown with amaranth that is resistant to soil toxicity and has high sorption properties.

The results of the experiments showed that the concentration of oil in the proposed method is reduced from 66.4 to $24.8 \mathrm{mg} / \mathrm{kg}$ in one season. At the same time, the number of hydrocarbons falls from 2680 to $362 \mathrm{mg} / \mathrm{kg}$.

Consequently, using biological resources having a high sorption capacity, it is possible to significantly reduce the toxicity of contaminated lands and restore their fertility.

\section{CONCLUSION}

Analyzing the data presented in the table, we can conclude that irrigation of oil-contaminated soils with an aqueous solution of para-aminobenzoic acid in a mixture with vegetable substances of stevia and a biological product Baikal EM-1 allows to restore the oiled areas.

\section{References}

[1] O. P. Melekhova, E. I. Sarapultseva, Biological control of environment. Bioindicator and biotesting. Moscow: Publishing Centre Akademiya, 2010

[2] O. P. Melekhova, E. I. Sarapul'tseva Biological control of environment. Genetic Monitoring. Moscow: Publishing Centre Akademiya, 2010.

[3] R. Schubert, Bioindicator of polluted abovgroun ecosystems. Moscow: Mir, 1988.

[4] L. A. Kovalenko, N. L. Lopaeva, The method of assessing the ecological status of agrobiocenosis in the zone of anthropogenic influence, Patent RF, no. 231433349, 2008.

[5] V. B. Zaalishvili, R. V. Osikin, The method of assessing the ecological status of a territory, Patent RF, no. 2375869, 2009.

[6] N. Yu. Velts, The method of environment's pollution by heavy metals Patent, no. 2257597, 2005

[7] V. B. Zaalishvili, S.A. Bekuzarova, O.P. Kozayeva, The method of assessing of inductrial pollution by heavy metals, Patent RF, no. 2485477, 2013

[8] V.N. Zelenkov, V.A. Gulschina, L.B. Tereshkina, Amaranthagrobiological portrait, Moscow: Izdaniye RAEN, 2009.

[9] E. Dominguez-Rosado, J. Pichtel, M. Coughilin, "Phytoremediation of Soil Contaminated with,Used Motor Oil: I. Enhanced Microbial Activities from Laboratory and Growth Chamber Studies, Environmental Engineering Science, vol. 2-4, no. 21. 2, pp.157-168.

[10] M.M. El-Sheekh, A.H. El - Naggar, M.E.H. Osman, A. Haieder, "Comparative Studies on the Green Algae Chlorella Homosphaera and Chlorella Vulgaris wit to Oil Pollution in the River Nile", Plant and Soil, vol. 267, 2004, pp.191-206.

[11] J.A. Percy, "Responeses of Arctic marine crustaceans to crude oil and oil-tainted food", Environ. Poll, vol. 10, pp. 155-162.

[12] J. Skujins, "History of abiotic soil enzyme research", In Soil Enzymes, Burns R.G.N. V. Ed. Academic Press Inc, 1978, pp. 1-49 